\title{
Nachdenken über van Gend en Loos: Reflexionstag beim EuGH
}

VB verfassungsblog.de/nachdenken-uber-van-gend-en-loos-reflexionstag-beim-eugh/

Alexandra Kemmerer So 19 Mai 2013

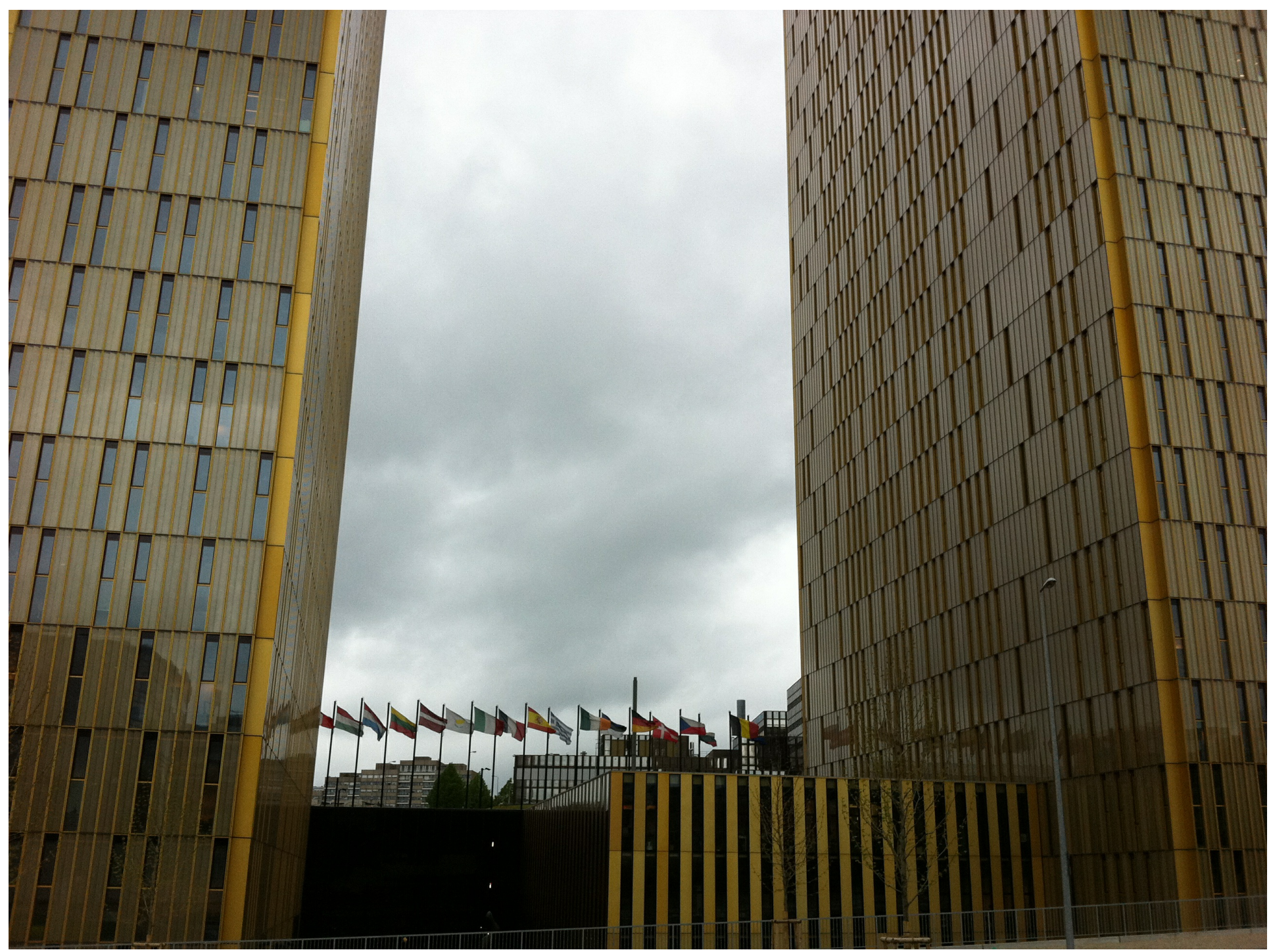

Wer eine Rechtsgemeinschaft gründen will, muss dafür Juristen gewinnen. Niemand wusste das besser als Michel Gaudet, von 1958 bis 1970 Generaldirektor des Juristischen Dienstes der Europäischen Kommission und einer der Architekten jener supranationalen Integration, die durch Recht begründet und vorangetrieben wurde.

Gaudet setzte alles daran, so viele Juristen wie möglich für das Europarecht und seine Institutionen zu gewinnen. Die zunächst von vielen als esoterisch empfundene Materie sollte zum selbstverständlichen Bestandteil des professionellen Diskurses werden. Gaudet bereiste Universitäten und Gerichte, holte interessierte Rechtswissenschaftler in die Hinterzimmer des Juristischen Dienstes und stellte „seed money“ zur Gründung wissenschaftlicher Vereinigungen und Fachzeitschriften bereit. Dazu gehörten die seit 1963 erscheinende „Common Market Law Review“ und die erstmals 1966 erschiene Zeitschrift „Europarecht“, für die auch das Auswärtige Amt in seine Schatulle griff.

Die Investition lohnte sich: Die europarechtlichen Fachgesellschaften wurden, wie die Politikwissenschaftlerin Karen 
Alter schreibt, das „Küchenkabinett“ des Europäischen Gerichtshofs. Die Vor- und Rezeptionsgeschichte des bahnbrechenden Urteils „van Gend en Loos“, mit dessen Verkündung das Luxemburger Gericht am 5. Februar 1963 Rechtsgeschichte schrieb (siehe auch: F.A.Z. vom 14. Mai 2013), ist ohne das weite juristische Feld der Richter und Anwälte, Rechtswissenschaftler und Ministerialbeamten nicht denkbar. Erst langsam wird dieser vielschichtige Kontext historisch und soziologisch erschlossen. Erste Studien zur Rezeption des Europarechts in einzelnen Mitgliedstaaten liegen vor; den Prozess der Europäisierung der deutschen Rechtsordnung hat unlängst die Frankfurter Rechtswissenschaftlerin Anna Katharina Mangold in einer gewichtigen Arbeit untersucht (dazu demnächst mehr, in der Juliausgabe des MERKUR).

Auf dem Luxemburger Kirchberg sind es aber noch immer die supranationalen Richter, die als Helden der Integrationsgeschichte vorgestellt werden. Jedenfalls auf den ersten Blick: Als der EuGH am 13. Mai anlässlich des Jubiläums zu einem „Tag der Reflexion“ einlud, erhielten die 400 Konferenzgäste einen Sonderdruck des historischen Urteils, samt Porträtfotos der weiland beteiligten Richter. Die hatten damals konstatiert, die Gemeinschaft stelle eine „neue Rechtsordnung des Völkerrechts dar, zu deren Gunsten die Staaten, wenn auch in begrenztem Rahmen, ihre Souveränitätsrechte eingeschränkt haben; eine Rechtsordnung, deren Rechtssubjekte nicht nur die Mitgliedstaaten, sondern auch die Einzelnen sind“. Auf die Individuen kommt es also an. Konsequenterweise finden sich daher in dem Bändchen auch Aufnahmen von Firmensitz und Fuhrpark des damaligen Klägers, des niederländischen Transportunternehmens van Gend \& Loos.

Die Hauptakteure des Geburtstagsfestes ( hier in voller Länge zum Nach-Sehen) waren die Europarechtler, denen Gerichtspräsident Vassilios Skouris (selbst Juraprofessor an der Aristoteles-Universität Thessaloniki) im großen Sitzungssaal das Podium überließ. In seiner Ouvertüre betonte Joseph Weiler, Professor für Europarecht an der New York University und ab Herbst Präsident des Europäischen Hochschulinstituts in Florenz, dass der Gerichtshof in „van Gend en Loos“ mit seiner Feststellung der unmittelbaren Anwendbarkeit des Gemeinschaftsrechts eine rechtspolitische Revolution eingeleitet und den Boden für jenen Vorrang des Gemeinschaftsrecht bereitet habe, der 1964 in „Costa/E.N.E.L.“ klar ausgesprochen wurde. Das im EWG-Vertrag vorgesehene Vorabentscheidungsverfahren mit seiner Verklammerung nationaler und supranationaler Gerichtsbarkeit war Voraussetzung der nachhaltigen Wirkung des Urteils - und profitierte von der Stärkung des Einzelnen, der zum Wächter des Gemeinschaftsrechts geworden sei. Die wirkliche Bedeutung von Vorrang und Unmittelbarkeit des Gemeinschaftsrechts sei indes eine moralische - "die konstitutionelle Toleranz, die Anforderung, dass wir zu einer europäischen Schicksalsgemeinschaft gehören”. Die Existenz dieser Gemeinschaft setze eine geteilte Kultur der Rechtsstaatlichkeit voraus, der Bereitschaft, sich an Recht zu halten und inm zur Durchsetzung zu verhelfen.

Dass man angesichts der Schuldenkrise an der Vertragstreue der Europäer durchaus Zweifel haben kann, schien Weiler nicht zu weiter zu befassen, stattdessen beklagte er das auch nach dem Vertrag von Lissabon fortdauernde Demokratiedefizit.

Die desaströse Finanzlage Europas blieb an diesem Tag vor den schweren Türen des Gerichtssaals. Nicht zuletzt am Umgang mit ihr dürfte sich aber die Bestandskraft der europäischen Rechtsgemeinschaft erweisen. Daniel Halberstam, Europarechtler an der University of Michigan Law School, wies darauf hin, dass es fünf Worte in "van Gend en Loos" seien, die das ganze System des Gemeinschaftsrechts verändert hätten - die Rede von individuellen Rechten, "welche die staatlichen Gerichte zu beachten" haben. Hier spreche der EuGH zu den nationalen Gerichten, betonte Halberstam, und als Appell an die nationalen (Verfassungs-)gerichte, den Zusammenhalt der Gemeinschaftsrechtsordnung nicht zu gefährden, konnte man auch die von dem Berliner Europarechtler Ingolf Pernice beschworene "Mitverantwortung" aller Gerichte im europäischen Verfassungsraum verstehen.

Der Europäische Gerichtshof indes nahm mit seinem "Tag der Reflexion" ganz offenkundig vor allem das Europa der Juristen in die Pflicht, Rechtswissenschaftler und Jurastudentinnen, Referendar und Stagiaires, Ministerialbeamte und Richterinnen nationaler Gerichte. Das war die Bürgerschaft, die den Weg zum Nachdenken nach Lxemburg gefunden hatte - und an die sich der Gerichtshof durch den Mund getreuer Europarechtler addressierte. Dass dies 
nicht ohne historisches Beispiel ist, ließ Jean-Victor Louis, emeritierter Europarechtler an der Freien Universität Brüssel, in seinen Schlußworten leise anklingen. Ob es noch einmal funktionieren wird, darüber sollte man nicht nur in Luxemburg gründlich nachdenken.

Diese Reflexion erschien, leicht gekürzt, in der Frankfurter Allgemeinen Zeitung vom 17. Mai 2013 (Nr. 113), S. 35; auf den ersten Blick scheint die von der Umbruchredaktion gewählte Überschrift "Tag der Reflexion. Feierstunde: Fünfzig Jahre Europäischer Gerichtshof" schlicht falsch, es steckt aber doch eine untergründige Wahrheit in diesem Irrtum: recht eigentlich kommt ein Gericht schließlich erst mit seiner ersten wichtigen Entscheidung in die Welt.

Foto: Alexandra Kemmerer

LICENSED UNDER CC BY NC ND

SUGGESTED CITATION Kemmerer, Alexandra: Nachdenken über van Gend en Loos: Reflexionstag beim EuGH, VerfBlog, 2013/5/19, http://verfassungsblog.de/nachdenken-uber-van-gend-en-loos-reflexionstag-beim-eugh/. 